\title{
Spatial analysis of soil properties using GIS based geostatistics models
}

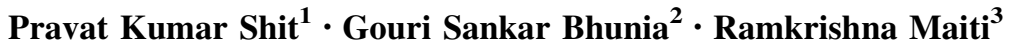

Received: 19 May 2016/Accepted: 4 June 2016/Published online: 18 June 2016

(C) Springer International Publishing Switzerland 2016

\begin{abstract}
Accurate assessment of the spatial variability of soil properties is key component of the agriculture ecosystem and environment modeling. The main objective of the present study is to measure the soil properties and their spatial variability. A combination of conventional analytical methods and geostatistical methods were used to analyze the data for spatial variability. In November 2014 a total of 32 soil samples were collected in the field through random sampling in Medinipur Sadar block of Paschim Medinipur district in West Bengal (India). Soil properties of $\mathrm{pH}$, electric conductivity (EC), phosphorus $(\mathrm{P})$, potassium $(\mathrm{K})$, and organic carbon (OC) were estimated using the standard analytical methods. A classical ordinary kriging (OK) interpolation was used for direct visualization of soil properties. The spatial distribution of $\mathrm{EC}, \mathrm{pH}$, and $\mathrm{OC}$ in soil are influenced by structural factors, such as climate, parent material, topography, soil properties and other natural factors. The semivariograms of the six soil properties were fit with exponential curve and root mean square error value is near about zero (0). Finally, spatial distribution and correlation between OC and other soil properties is shown by overlay of maps in GIS environment. The present study suggest that the OK interpolation can directly reveal the
\end{abstract}

Pravat Kumar Shit

Pravatgeo2007@gmail.com

1 Department of Geography, Raja N.L.Khan Women's College, Gope Palace, Medinipur, West Bengal 721102, India

2 Bihar Remote Sensing Application Center, IGSC-Planetarium, Adalatganj, Bailey Road, Patna, Bihar 800001, India

3 Department of Geography and Environment Management, Vidyasagar University, Medinipur, West Bengal 721102, India spatial distribution of soil properties and the sample distance in this study is sufficient for interpolation.

Keywords Soil properties - Organic carbon · GIS · Ordinary kriging $\cdot$ Semivariograms

\section{Introduction}

Sustainable land management requires reliable information on the spatial distribution of soil properties affecting both landscape process and services (Lin et al. 2005; Shibu et al. 2006). In conventional soil survey soil properties are recorded at representative sites and assigned to entire mapping unit, which are delineated using both physiographic and geopedologic approaches. Although soil surveyors are very well aware of the spatial variability of soil properties, conventionally prepared soil maps do not reflect it as soil units are limited by boundaries (Heuvelink and Webster 2001). But in nature the soil properties are highly variable spatially (Burrough 1993) and for accurate estimation of soil properties these continuous variability should be considered. The traditional method of soil analysis and interpretation are laborious, time consuming, hence becoming expensive. Geostatistical techniques (kriging) are widely recognized as an important spatial interpolation technique in land resource inventories (Hengl et al. 2004; Bhunia et al. 2016).

Geostatistical methods quantify spatial distribution and variability based on the spatial scale of the study area, distance between sampling points and spatial pattern of modeling semivariograms. They have been widely applied to evaluate spatial correlation in soils and to analyze the spatial variability of soil properties, such as soil physical, chemical and biological properties (Fromm et al. 1993; 
Wigginton et al. 2000; Vieira et al. 2007; Zheng et al. 2009; Liu et al. 2014).

In India majority of soil maps were prepared by conventional methods and a very little work has been done so far to use the modern spatial prediction techniques in this regard (Saha et al. 2012; Pal et al. 2014; Behera and Shukla 2015; Tripathi et al. 2015; Bhunia et al. 2016). The accurate estimation of spatial distribution of soil properties [soil $\mathrm{pH}$, organic carbon (OC), electrical conductivity, phosphorous, potassium, etc.] is important in precision agriculture and is one of the bases for decision and policy makers to make plans and strategies. So, research in environmental monitoring, modeling and precision agriculture need good quality and inexpensive soil data. The aim of this paper is to evaluate the potential for measuring soil properties [electric conductivity (EC), $\mathrm{pH}, \mathrm{K}, \mathrm{P}$, and $\mathrm{OC}]$ and its spatial variability using geostatistical methods.

\section{Materials and methods}

\section{Study area}

The present study was conducted in Medinipur Sadar block of Paschim Medinipur district in West Bengal (India) extending between $22^{\circ} 23^{\prime} 45^{\prime \prime} \mathrm{N}-22^{\circ} 32^{\prime} 50^{\prime \prime} \mathrm{N}$ latitude and $87^{\circ} 05^{\prime} 40^{\prime \prime} \mathrm{E}-87^{\circ} 31^{\prime} 01^{\prime \prime} \mathrm{E}$ longitude covering an area of $353 \mathrm{~km}^{2}$ (Bhunia et al. 2016). The geomorphology of the block is undulating surface topography predominantly covered by laterite soil. The sand, silt and clay contents of the soil are 45, 35 and $20 \%$, respectively. The average annual precipitation in the study area is $1,800 \mathrm{~mm}$. In addition, $70 \%$ of the annual rainfall is this region occurs between June and August. During these months the rainfalls is intense and causes extensive erosion. The study area is under two main land use types cover agricultural land $(56.91 \%)$ and forest land $(24.76 \%)$.

\section{Soil sampling and measurement}

In November 2014 a total of 32 soil samples were collected in the field through random sampling from whole of the study area. A portable global positioning system (GPS) was used to collect each sample site. The undisturbed soil samples at depths of 0-20 cm, was collected with five soil cores each, and well mixed into a composite soil sample. Soil samples were air dried and passed through a $2 \mathrm{~mm}$ sieve for laboratory analysis of soil texture. Soil pH, EC, phosphorus $(\mathrm{P})$, potassium $(\mathrm{K})$, and soil OC were determined using the standard analytical methods (Table 1).

\section{Geostatistical methods}

Geostatistical method is a spatial distribution and variability analysis method that was developed from classical statistics. The ordinary kriging (OK) interpolation method was used for prediction of the values of the unmeasured sites (un-samples locations) $x_{0}$ by assuming the $z^{*}\left(x_{0}\right)$ equals the line sum of the known measured value (field measured value). Kriging process is calculated by the following equation (Wang 1999):

$Z^{*}\left(x_{0}\right)=\sum_{i=1}^{n} \lambda_{i} z\left(x_{i}\right)$

Where $z^{*}\left(x_{0}\right)$ is the predicted value at position $x_{0}, Z\left(x_{i}\right)$ the known value at sampling site $x_{i}, \lambda_{i}$ the weighting coefficient of the measured site and $n$ is the number of sites within the neighborhood searched for the interpolation.

Semivariograms were used as the basic tool to examine the spatial distribution structure of the soil properties. Based on the regionalized variable theory and intrinsic hypotheses (Nielsen and Wendroth 2003), a semivariogram is expressed as:

$\gamma(h)=\frac{1}{2 N(h)} \sum_{i=1}^{N(h)}\left[Z\left(x_{i}\right)-Z\left(x_{i}+h\right)\right]^{2}$

where $\gamma(h)$ is the semivariance, $h$ the lag distance, $Z$ the parameter of the soil property, $N(h)$ the number of pairs of locations separated by a lag distance $h, Z\left(x_{i}\right)$, and $Z\left(x_{i}+h\right)$ are values of $Z$ at positions $x_{i}$ and $x_{i}+h$ (Wang and Shao 2013). The empirical semivariograms obtained from the data were fitted by theoretical semivariogram models to produce geostatistical parameters, including nugget variance $\left(C_{0}\right)$, structured variance $\left(C_{1}\right)$, sill variance $\left(C_{0}+C_{1}\right)$, and distance parameter $(\lambda)$. The nugget/sill ratio, $C_{0} /\left(C_{0}+C_{1}\right)$, was calculated to characterize the spatial dependency of the values. In general, a nugget/sill ratio $<25 \%$ indicates strong spatial dependency and $>75 \%$ indicates weak spatial dependency; otherwise, the spatial dependency is moderate (Cambardella et al. 1994).

\section{Cross-validation}

Cross-validation technique was adopted for evaluating and comparing the performance of $\mathrm{OK}$ interpolation method. The sample points were arbitrarily divided into two datasets, with one estimate mean value against measured mean were used to validate the model. The root mean square error (RMSE) is error based measures to evaluate the accuracy of interpolation methods.

$\mathrm{RMSE}=\sqrt{\frac{\sum_{i=1}^{N}\left(0_{i}-S_{i}\right)^{2}}{N}}$ 
Table 1 Analytical methods of estimation of different physiochemical parameters of soil

\begin{tabular}{ll}
\hline Parameters & Methods \\
\hline Electrical conductivity (EC) & Conductivity bridge method (Richards 1954) \\
Soil pH & Digital pH meter \\
Potassium (K) & Flame spectrophotometer (Jackson 1958) \\
Organic carbon (OC) & Walkley-Black wet oxidation method (Nelson and \\
& Sommers 1996; Bao 2000) \\
Phosphorus (P) & Spectrophotometer (Bremner 1996)
\end{tabular}

Table 2 Geo-statistical parameters of the fitted semivariogram models for soil properties and cross-validation statistics

\begin{tabular}{lllllllr}
\hline Soil property & Model & Nugget $\left(C_{0}\right)$ & Sill $\left(C_{0}+C\right)$ & Range $(\mathrm{m})$ & Nugget/sill & $R^{2}$ & RMSE \\
\hline P $(\mathrm{ppm})$ & Exponential & 0.26 & 3.309 & 1,100 & 0.08 & 0.58 & 0.480 \\
K $(\mathrm{ppm})$ & Exponential & 0.24 & 4.662 & 1,131 & 0.05 & 0.53 & 0.590 \\
$\mathrm{pH}$ & Exponential & 0.06 & 0.218 & 2,018 & 0.28 & 0.44 & 0.365 \\
Organic carbon $(\%)$ & Exponential & 0.54 & 0.970 & 2,219 & 0.56 & 0.39 & 0.858 \\
EC $(\mu \mathrm{s})$ & Exponential & 0.04 & 1.040 & 925 & 0.04 & 0.61 & 0.381 \\
\hline
\end{tabular}

$R^{2}$ coefficient of determination, $R M S E$ root mean square error

Where $0_{i}$ is observed value and $S_{i}$ is the predicted value, $N$ is the Number of samples.

\section{Result and discussion}

\section{Geostatistical analysis}

Table 2 shows the soil properties where variable characteristics was generated from semivariogram model. $C_{0}$ is the nugget variance; $C$ is the structural variance, and $C_{0}$ $+C$ represents the degree of spatial variability, which affected by both structural and stochastic factors (Fig. 1). The higher ratio indicates that the spatial variability is primarily caused by stochastic factors, such as fertilization, farming measures, cropping systems and other human activities. The lower ratio suggests that structural factors, such as climate, parent material, topography, soil properties and other natural factors, play a significant role in spatial variability. The value of $<0.25,0.25-0.75$, and $>0.75$ can show strong, moderate and weak spatial autocorrelation in soil properties, respectively. As shown in Table 2, the $C_{0} /$ $C_{0}+C$ ratio values for $\mathrm{P}, \mathrm{K}, \mathrm{pH}, \mathrm{OC}$ and $\mathrm{EC}$ were 0.08 , $0.05,0.28,0.56$, and 0.04 , respectively. The nugget $/$ sill ratio were between 25 and $75 \%$ of OC, indicating moderate spatial correlation with 2,219 $\mathrm{m}$ ranges and impact of stochastic and structural factors. The $C_{0} / C_{0}+C$ ratio were less $25 \%$ in the four soil properties such as $\mathrm{P}, \mathrm{K}, \mathrm{pH}$, and EC indicates a strong spatial correlation. The spatial correlation was apparent in the $925-2,018 \mathrm{~m}$ ranges and was affected by structural factors.
The semivariance function model fits exponential curve for each soil properties. The exponential curve gradually increased with increasing spatial distance before stabilizing. All five soil properties have coefficients of determination $R^{2}$ values of $0.39-0.61$ and a small RMSE. The $R^{2}$ was calculated to measure the goodness of fit. The $R^{2}$ of all variables, except for $\mathrm{pH}$, and $\mathrm{OC}$ were $>0.5$, indicating a good fit (Table 2). The $\mathrm{pH}$ and OC had a moderate fit, with $R^{2}$ values of 0.44 and 0.39 , respectively. The RMSE were all approximately near to 0 , but the theoretical model for $\mathrm{K}$ and OC showed RMSE values of 0.590 and 0.858 , respectively. These results indicate that the theoretical model was an adequate representation of the spatial structural properties of soil.

\section{Spatial distribution of soil properties}

Figure $2 \mathrm{a}-\mathrm{d}$ shows the spatial distribution of soil properties of $\mathrm{EC}, \mathrm{pH}, \mathrm{K}, \mathrm{P}$ and $\mathrm{OC}$ using $\mathrm{OK}$ interpolation method. An OK technique was used to switch point soil samples into continuous fields of soil properties. The spatial correlation map of soil properties $(\mathrm{EC}, \mathrm{pH}, \mathrm{K}$, and $\mathrm{P}$ ) and measured OC was produced, compared and analyzed for the results. Spatial variability maps among the soil $\mathrm{pH}, \mathrm{EC}$, $\mathrm{K}, \mathrm{P}$ and predicted OC was prepared using ArcGIS to represent the dependence of OC (Fig. 2). Concentration of OC was observed in the north-western part of the study area. Soil $\mathrm{pH}$ found to be an important factor in the analysis of the soil inorganic carbon (SIC), but its contribution towards organic carbon cannot be overruled. The spatial map of $\mathrm{pH}$ is generated from the measured $\mathrm{pH}$ value from the collected samples in the study sites. To the central and 

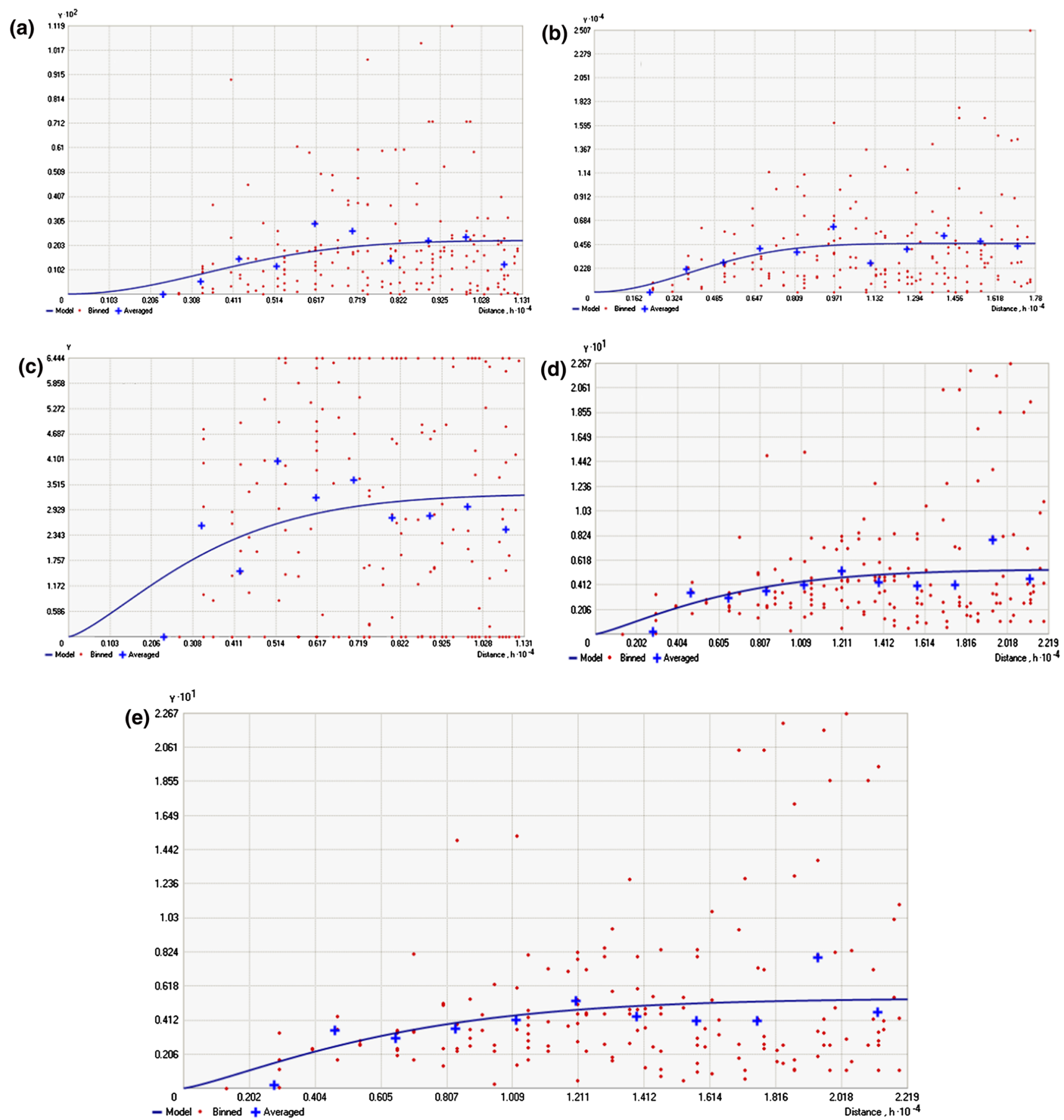

Fig. 1 Semivariogram parameters of best-fitted theoretical model to predict soil properties, a EC, b K, c P, d soil pH, and e SOC

northeastern portion of the study site, higher $\mathrm{pH}$ is concentrated.

The value of $\mathrm{P}$ was highly concentrated in the eastern and south western part, whereas the higher OC was observed in the northwestern corner of the study site. Spatial distribution of $\mathrm{P}$ did not varied extremely with organic carbon; however, well reflected changes were observed in spatial distribution for $\mathrm{OC}$ and $\mathrm{pH}$. The EC varied with organic carbon and some portion showed concentrated EC. The $\mathrm{K}$ value showed some pockets of concentration. However, regression analysis was preformed between soil properties and predicted OC. The statistical regression among the predicted $\mathrm{OC}$ and $\mathrm{EC}, \mathrm{pH}$, $\mathrm{K}$, and $\mathrm{P}$ of $R^{2}$ values were $0.32,0.45,0.38$ and 0.41 , respectively. These results suggest that the certain management practices, e.g., minimum tillage, cover crops, and 

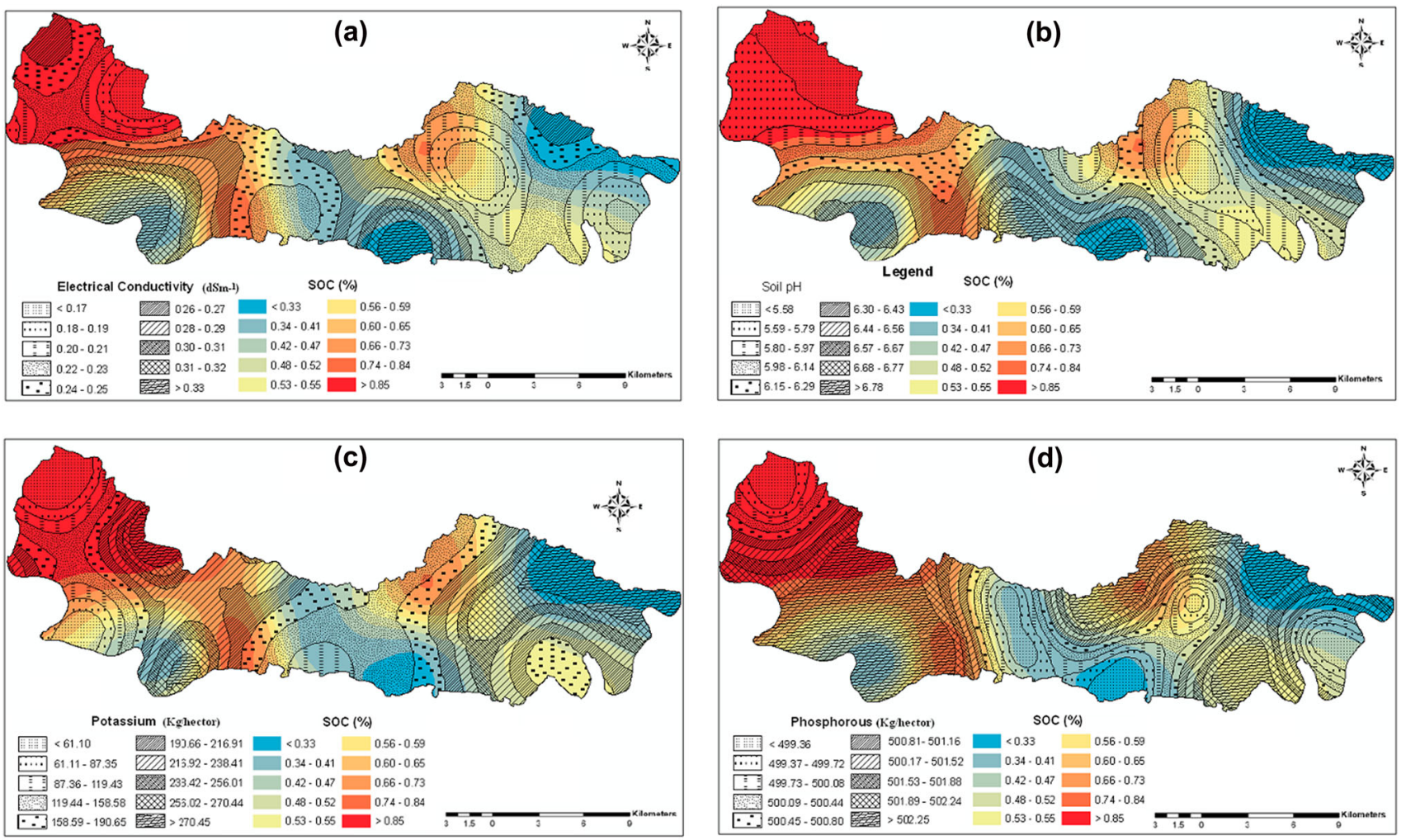

Fig. 2 Spatial relationship between SOC and soil properties, a EC and SOC, b soil pH and SOC, $\mathbf{c}$ K and SOC, and d P and SOC

rotations, are to be used to recover $\mathrm{OC}$ of the topsoil in the study area. The greater amount of soil OC was perhaps due to the maximum concentration of root mass, waste material and secrete root exudates, growing physical steadiness and microbial activity (Holeplass et al. 2004; Kukal et al. 2008). In our analysis, it was found that storage of OC in soil was mainly influenced by structural factors, such as climate, parent material, topography, soil properties and other natural factors played a significant role in spatial variability.

\section{Conclusion}

Understanding the spatial distribution and accurate mapping of soil properties at large scale are essential for precision farming, environmental monitoring, and modeling. This study showed that geostatistical models were fitted for six soil properties, namely phosphorus $(\mathrm{P})$, potassium $(\mathrm{K})$, $\mathrm{pH}$, electrical conductivity (EC), and organic carbon (OC). Cross-validation of variogram models through OK showed that spatial prediction of soil properties is better than assuming the mean of the observed values at any unmeasured location. Finally, six prediction maps were developed using best fit semivariogram models with OK. Our results suggest that the ordinary kriging interpolation can directly reveal the spatial distribution of soil properties and the sample distance in this study is sufficient for interpolation. However, future studies are needed to clarify the spatial variability on the larger scale and better understand the factors controlling spatial variability of soil properties.

\section{References}

Bao SD (2000) Soil and agricultural chemistry analysis. China Agriculture Press, Beijing, p 495

Behera SK, Shukla AK (2015) Spatial distribution of surface soil acidity, electrical conductivity, soil organic carbon content and exchangeable potassium, calcium and magnesium in some cropped acid soils of India. Land Degrad Dev 26:71-79

Bhunia GS, Shit PK, Maiti R (2016) Comparison of GIS-based interpolation methods for spatial distribution of soil organic carbon (SOC). J Saudi Soc Agric Sci. doi:10.1016/j.jssas.2016. 02.001

Bremner JM (1996) Nitrogen-total. In: Sparks DL (ed) Methods of soil analysis-part 3-chemical methods. Soil Science Society of America, American Society of Agronomy, Madison, pp 1085-1121

Burrough P (1993) Soil variability: a late 20th century view. Soils Fertil 56:529-562

Cambardella CA, Moorman TB, Novak JM, Parkin TB, Karlen DL, Turco RF, Konopka AE (1994) Field-scale variability of soil properties in central Iowa soils. Soil Sci Soc Am J 58:1501-1511

Fromm H, Winter K, Filser J (1993) The influence of soil type and cultivation system on the spatial distributions of the soil fauna 
and microorganisms and their interactions. Geoderma 60:109-118

Hengl T, Rossiter DG, Stein A (2004) Soil sampling strategies for spatial prediction by correlation with auxiliary maps. Aust J Soil Res 41(8):1403-1422

Heuvelink GBM, Webster R (2001) Modeling soil variation: past, present, and future. Geoderma 100(3-4):269-301

Holeplass H, Singh BR, Lal R (2004) Carbon sequestration in soil aggregates under different crop rotation and nitrogen fertilization in an inceptisol in southeastern Norway. Nutr Cycl Agroecosyst 70:167-177

Jackson ML (1958) Soil chemical analysis. Prentice-Hall, Englewood Cliffs, pp 111-133

Kukal SS, Kaur M, Bawa SS (2008) Erodibility of sandy loam aggregates in relation to their size and initial moisture content under different land uses in semi-arid tropics of India. Arid Land Res Manag 22:216-227

Lin H, Wheeler D, Bell J, Wilding L (2005) Assessment of soil spatial variability at multiple scales. Ecol Model 182:271-290

Liu L, Wang H, Dai W, Lei X, Yang X, Li X (2014) Spatial variability of soil organic carbon in the forestlands of northeast China. J For Res 25(4):867-876

Nelson DW, Sommers LE (1996) Total carbon, organic carbon, and organic matter. In: Sparks DL, Page AL et al (eds) Methods of soil analysis, part 3. Chemical methods, vol 5. Soil Science Society of America Book Series, Wisconsin, pp 961-1010

Nielsen DR, Wendroth O (2003) Spatial and temporal statisticssampling field soils and their vegetation. Catena Verlag GMBH, Reiskirchen

Pal S, Manna S, Aich A, Chattopadhyay B, Mukhopadhyay SK (2014) Assessment of the spatio-temporal distribution of soil properties in East Kolkata wetland ecosystem (A Ramsar site: 1208). J Earth Syst Sci 123(4):729-740
Richards LA (1954) Diagnosis and improvement of saline and alkali soils. Agriculture handbook 60. US Department of Agriculture, Washington, DC, p 160

Saha D, Kukal SS, Bawa SS (2012) Soil organic carbon stock and fractions in relation to land use and soil depth in the degraded Shiwaliks hills of lower Himalayas. Land Degrad Dev. doi:10. 1002/ldr.2151

Shibu M, Leffelaar P, Van Keulen H, Aggarwal P (2006) Quantitative description of Soil organic carbon matter dynamics-a review of approaches with reference to rice-based cropping systems. Geoderma 137:1-18

Tripathi R, Nayak AK, Shahid M, Raja R, Panda BB, Mohanty S, Kumar A, Lal B, Gautam P, Sahoo RN (2015) Characterizing spatial variability of soil properties in salt affected coastal India using geostatistics and kriging. Arab J Geosci. doi:10.1007/ s12517-015-2003-4

Vieira VA, Mello CR, Lima JM (2007) Spatial variability of soil physical attributes in small watershed. Ciencia e Agrotecnologia 31(5):1477-1485 (in Portuguese)

Wang ZQ (1999) Geostatistics and its applications in ecology. Beijing Science Press, Beijing

Wang YQ, Shao MA (2013) Spatial variability of soil physical properties in a region of the Loess Plateau of PR China subject to wind and water erosion. Land Degrad Dev 24(3):296-304

Wigginton JD, Lockaby BG, Trettin CC, Nelson EA, Kolka RK, Wisniewski J (2000) Soil organic matter formation and sequestration across a forested floodplain chronosequence. In: Proceeding of workshop held at Clemson University, 12-14 April 1999, pp 141-155

Zheng Z, Zhang FR, Ma FY (2009) spatiotemporal changes in soil salinity in a drip irrigated field. Geoderma 149:243-248 